Revista de Filología Románica

ISSN: 0212-999X

http://dx.doi.org/10.5209/RFRM.63512

\title{
Estructuras participiales y gerundiales en el castellano del s. XVI: caracterización sintáctica y estatuto variacional
}

\author{
Santiago Del Rey Quesada ${ }^{1}$
}

Recibido: 12 de agosto de 2017/ Aceptado: 15 de septiembre de 2018

Resumen. El trabajo que presentamos analiza, en un primer apartado, la tipología de participios y gerundios en las lenguas romances y sus líneas de evolución desde el latín, trazando un exhaustivo estado de la cuestión, además, sobre la adscripción variacional de estas estructuras como esquemas más o menos típicos de la escrituralidad. Un segundo apartado describe los problemas y posturas enfrentadas entre los especialistas a la hora de caracterizar sintácticamente las construcciones absolutas de participio y de gerundio; en tal descripción se valoran críticamente el criterio de copresencia de sujeto nominal/pronominal + forma no personal y el criterio de correferencialidad entre el sujeto de la construcción absoluta y el sujeto de la oración regente. Un tercer apartado ensaya la aplicación de una tipología a un corpus de textos castellanos en prosa, tanto traducidos como originales, del siglo XVI, poniendo en evidencia las dificultades e inconsistencias de las taxonomías cerradas cuando el análisis se aborda desde una perspectiva discursiva.

Palabras clave: gerundio; participio; latinismo sintáctico; construcción absoluta; análisis histórico del discurso.

\section{[en] Participle and Gerundial Constructions in 16th Century Spanish: Syntactic Features and Variational Status}

\begin{abstract}
This article presents, firstly, the typology of participles and gerunds in Romance languages by discussing their Latin origins within a comprehensive state of the art. The variational status of participle and gerundial constructions is also at issue in this paper, insofar it is still unclear, to what extent these structures are strategies typical of formal linguistic manifestations. Secondly, the different - and often opposed - positions scholars assume when syntactically describing absolute participle and gerundial constructions are critically pointed out. In this respect, we examine the syntactic behaviour of absolute clauses, focusing especially on two criteria: the co-presence of nominal/pronominal subject + non-finite form and the coreferentiality between the subject in the absolute clause and the subject of the main sentence. A third section aims to apply a typology of participle and gerundial constructions to a corpus containing translated and non-translated Castilian texts in prose from the 16th century. By doing this, we will show the difficulty and inconsistence of static taxonomies if the analysis is conducted from a discoursive point of view.
\end{abstract}

Key words: Gerund, Participle; Latinate Syntax; Absolute Construction; Historical Discourse Analysis.

1 Departamento de Lengua Española, Lingüística y Teoría de la Literatura. Facultad de Filología - Universidad de Sevilla

sdelrey@us.es

Esta investigación fue realizada en el marco del proyecto "Tradiciones discursivas, tradiciones idiomáticas y unidades de análisis del discurso en la historia del español moderno" (FFI2014-51826-P). 
Sumario: 1 . Introducción y corpus de trabajo. 2. Tipos de participios y gerundios: contextos sintácticos de aparición. 3. Clasificación de los usos participiales y gerundiales y su reflejo en el corpus. 4. Conclusiones y tareas pendientes

Cómo citar: Del Rey Quesada, S. (2019). Estructuras participiales y gerundiales en el castellano del s. XVI: caracterización sintáctica y estatuto variacional, en Revista de Filología Románica 36, 179-199.

\section{Introducción y corpus de trabajo}

El uso de participios y gerundios como procedimiento subordinativo ha sido analizado desde diferentes perspectivas, desde la meramente formal hasta la discursiva, pasando por los acercamientos fundamentalmente estilísticos, y todo ello en estudios de índole tanto diacrónica como sincrónica. ${ }^{2} \mathrm{Si}$ bien la presencia de estructuras participiales - sobre todo en función adjetiva- y gerundiales no es extraña a la comunicación oral incluso en situaciones de escasa formalidad, ${ }^{3}$ el uso del participio y del gerundio se relaciona de forma prototípica con un registro específico de lengua, precisamente el que se da en situaciones propias de la distancia comunicativa. En diferentes tradiciones discursivas desarrolladas en el ámbito de la escrituralidad de las lenguas romances, ${ }^{4}$ el uso, y con frecuencia el abuso, de participios y gerundios, especialmente en posición incidental-volveremos sobre este punto- dentro del enunciado, se ha explicado como un procedimiento discursivo que emula giros sintácticos ${ }^{5}$ propios del latín clásico, postclásico y medieval. La proverbial concisión de la lengua latina se basa en gran medida en las formas no finitas del verbo, entre ellas muy especialmente en el infinitivo ${ }^{6}$ y en el participio, que despliegan en la lengua de los clásicos una ductibilidad y polivalencia de funciones no heredadas plenamente por las lenguas romances y seguramente alejadas de los usos cotidianos del latín.

2 Muchas de las referencias bibliográficas incluidas en este trabajo son representativas de las diferentes perspectivas de investigación que acabo de mencionar.

3 Cf. Narbona (2000[2015]: 121). Con frecuencia se han aducido al respecto las cláusulas absolutas de participio constituyentes de enunciados proverbiales, como muerto el perro, se acabó la rabia. Sin embargo, el carácter oral -en el sentido concepcional (cf. Koch/Oesterreicher 1990[2011])- de los refranes y proverbios es bastante cuestionable (cf. Lázaro Carreter 1980, Del Rey 2015: 240-241).

4 El concepto de 'escrituralidad' y 'oralidad' al que aludo aquí, como también indico en la anterior nota, se refiere al modelo propuesto por Koch/Oesterreicher (1990[2001]), quienes revisan la idea del 'diasistema' coseriano concluyendo que la variedad oral/escrito, que los autores conciben como un continuum entre la inmediatez y la distancia comunicativas, es la pieza teórica fundamental de la arquitectura de una lengua. Cuando hablo de estatuto variacional en este artículo aplicado a determinadas unidades sintácticas me refiero al lugar que dichas unidades ocupan en el continuum concepcional entre oralidad y escritura que describe este modelo.

5 Es lo que Tesi (2001: 95) denomina para el italiano "stile periodico o ipotattico", caracterizado por las oraciones largas y los períodos muy articulados. El estilo gerundial y participial también es considerado como emulación de la lengua latina en portugués por Da Silveira (1955: 201). Cf., asimismo, Tarriño Ruiz/Baños Baños (2009) y Del Rey (2016a: 431).

6 Mientras que el infinitivo redujo sus posibilidades hipotácticas en el paso del latín a las lenguas romances (piénsese en el accusativus cum infinitivo (AcI), siempre minoritario en los procedimientos subordinativos en épocas pasadas de las lenguas romances -cf., para una perspectiva panrománica, Stein (1997: 145-152)-, y hoy prácticamente extinto), el participio conservó más entidad discursiva en el ámbito de la distancia, donde también funciona todavía como elemento verbal. 
Se trata de un tipo de imbricación sintética ${ }^{7}$ que atrae a los escritores de las lenguas romances sobre todo a partir del Humanismo y que redunda en una complicación del período.

En este trabajo nos interesamos especialmente por las características sintácticas de las construcciones participiales y gerundiales que suelen encontrarse en la prosa historiográfica y doctrinal del s. XVI. Si bien es este un problema difícil de solucionar cuando tratamos con la lengua del pasado, se discutirá el estatus latinizante de ciertas estructuras en un corpus de textos castellanos del Siglo de Oro; en este contexto, concedemos un papel protagonista al análisis de las construcciones absolutas (CA), tanto de participio como de gerundio, pero sin dejar de lado determinados esquemas que, si bien basándonos en un criterio estrictamente sintáctico no suelen considerarse absolutos o, al menos, absolutos prototípicos, se relacionan con las CA e imbrican en los períodos en que estas suelen encontrarse. Nos referiremos también a estructuras ya asistemáticas en las lenguas romances que, sin embargo, fueron posibles en épocas pasadas y que, a lo más, se han conservado como fósiles lingüísticos o fórmulas estereotipadas en determinados lenguajes de especialidad.

Las obras castellanas que analizamos en este estudio corresponden a dos autores erasmistas: Alonso Fernández de Madrid, Arcediano del Alcor, y Bernardo Pérez de Chinchón. La elección de estos autores está motivada por la circunstancia de que ambos compusieron tanto obras originales como traducciones, lo que nos proporciona un contexto comparativo ideal para el tipo de análisis que abordaremos en las siguientes secciones. Nos apoyaremos en dos obras traducidas, ambas desde originales de Erasmo: del primero de los escritores citados, el Enquiridion o Manual del cavallero christiano (a. 1526) y, del segundo, La lengua de Erasmo nuevamente romançada por muy elegante estilo (1531). Asimismo, estudiaremos dos textos de autoría propia: la Silva palentina (ca. 1536-1539) de Alonso Fernández de Madrid y los Diálogos cristianos (1535) de Bernardo Pérez de Chinchón. ${ }^{8}$ En las cuatro obras que estudiamos, la proporción de texto analizada alcanza un total de ca. 23550 palabras. Como parte de texto no traducido también hay que considerar el prólogo a las traducciones en ambos escritores -ca. 4085 palabras en el Enquiridion y ca. 3460 en la Lengua -. El objetivo del trabajo no es puramente estadístico, pues el criterio cualitativo es esencial en esta investigación. No obstante, se facilitarán algunos porcentajes a pie de página para dar cuenta del diferente grado de aparición de las estructuras analizadas en cada caso.

\footnotetext{
Lorian (1973: 141-142), en su estudio sobre la prosa francesa del siglo XVI, habla de dos tipos de imbricación, la sintética y la analítica, ambos implicados en el deseo "d'illustrer la langue et le style" (p. 142). La diferencia entre sinteticidad y analiticidad -"syntheticity" y "analiticity"- es fundamental en la obra de Ledgeway (2012), según el cual cabría hablar de un continuum entre los dos conceptos en el que el latín sería exponente prototípico de tendencias sintéticas y las lenguas romances de tendencias analíticas, si bien concede (p. 15) que 'sinteticidad' y 'analiticidad' son conceptos que no deben ser atribuidos a lenguas en general sino a construcciones concretas.

8 En los ejemplos contenidos en el apartado §3.2, uso las abreviaturas Ench para referirme al texto original erasmiano (Enchiridion militis christiani), Enqu para la traducción del Arcediano del Alcor (Enquiridion o Manual del cavallero christiano), Li para el original de la Lingua de Erasmo, Le para la traducción de Pérez de Chinchón ( $L a$ lengua de Erasmo nuevamente romançada por muy elegante estilo) y Si para la Silva palentina del Arcediano.
} 


\section{Tipos de participios y gerundios: contextos sintácticos de aparición}

Si bien en latín habría que considerar las formas del gerundivo y del supino, junto con las del gerundio y las del infinitivo -muy variadas estas últimas en función del tiempo y la diátesis-, en las lenguas romances, apartadas de momento las estructuras infinitivas que no son competencia de este estudio, podemos distinguir distintos tipos de participios y de gerundios.

\subsection{Participio de presente}

El participio de presente latino -amans, -ntis- no tuvo continuidad en el castellano ni en el toscano, ${ }^{9}$ mientras que la ruptura con la lengua madre a este respecto es controvertida para el caso del francés. ${ }^{10}$ Los participios de presente en italiano (cf. Segre 1963: 76; Pfister 1978: 76; De Roberto 2012: 115-169), en portugués (Da Silveira Bueno 1955: 201; Loporcaro/Pescia/Ramos 2004) y en castellano (cf. Santiago 1979: 577; Lapesa 2000: 117; Meilán 1991a; Muñío Valverde 1995; Campos Souto 2001; Azofra 2006; Pons Rodríguez 2015b; Pountain 2010; Gil 2012) han sido considerados imitaciones latinizantes que aparecen en la lengua literaria sobre todo a partir de la época humanística. ${ }^{11}$ Efectivamente, si bien el participio de presente había producido formas adjetivales - por ejemplo it. pesante, pt. prazente, esp. ardiente-, y sustantivos invariables en género (excepto en el caso del francés) -it. tenente, pt. navegante, esp. contribuyente-, el funcionamiento verbal de estas estructuras suponía una clara transgresión de la norma debido a influjo latinizante.

También su uso en construcciones absolutas ${ }^{12}$ demuestra un cariz más estereo-

9 A propósito de las estructuras participiales dependientes de verbos de percepción en italiano, Greco (2016: 386, n. 38) postula la posibilidad de que estas se dieran en el romance por vía de continuidad y no por recuperación culta.

10 Acerca de la controversia existente sobre las formas en -ant, cf. un exhaustivo análisis en Weerenbeck (1927), un útil estado de la cuestión en Halmøy (1982) así como un pequeño resumen en De Cesare y Brianti (2016: 264-265). Lecointe (1997) admite la dificultad de delimitación entre gerundio y participio de presente en sintagmas no preposicionales. Una completa descripción de la evolución morfológica de las estructuras en -ant, sobre todo en lo que atañe a la variación de género y número, y de la tradición gramaticográfica se encuentra en Sarré (2000). Hunnius (2006) reconsidera el problema desde una perspectiva diacrónica poniendo énfasis en el carácter latinizante de las estructuras de participio de presente sobre todo a partir de la época humanística. Sostiene que la dificultad de diferenciación entre el gerundio y el participio francés se debe a la homonimia de las formas. Si tenemos en cuenta que los usos gerundiales de las estructuras en -ant no siempre son marcados por la preposición en en la historia del francés (Sarré 2000: 40), al menos no sistemáticamente hasta el s. XVII (Hunnius 2006: 89), tal dificultad se ve acrecentada. Gran parte de la discusión descansa sobre la incógnita de si las formas en -ant derivan del participio presente o del gerundio. De acuerdo con el esquema propuesto por Sneyders de Vogel (1919: 199), las formas patrimoniales francesas en -ant provienen del gerundio (amando > amant), mientras que a partir del s. XIV, con la llegada del Humanismo, se produciría por influencia culta del participio de presente, como quiere Lausberg (1962: § 814, p. 210), una "Partizipialisierung des etymologischen Gerundiums”. Müller-Lancé (1994: 53) adopta una posición más ecuménica al considerar que, en el fondo, se trata de un problema de terminología.

11 Más allá del debate sobre las formas gerundiales o participiales en -ant para el francés, hay acuerdo más o menos generalizado en tildar de latinizante el (ab)uso de estas estructuras como procedimiento subordinativo en el Renacimiento (cf. Lardon y Thomine 2009: 294). Así lo expresa Lorian (1973: 215): "le participe conjoint en -ant est un instrument permettant à la fois d'allonger la phrase, de donner un coup de pouce à la narration, et de doter celle-ci d'une saveur latiniste".

12 Tampoco hay acuerdo sobre si las construcciones absolutas que albergan una forma en -ant en francés deben ser consideradas participiales o gerundiales. Mientras Brunot $\left({ }^{4} 1933: 273\right)$ y Weerenbeck $(1927: 290)$ entienden que 
tipado que el que podría adscribirse a otros tipos de CA. Según De Roberto (2012: 161), para el italiano, ya en época antigua suponen un fenómeno en regresión, y a lo largo de la Edad Media se mantienen sobre todo en fórmulas fijadas propias de tradiciones discursivas específicas, como la de la lengua jurídica -del tipo regnante il re-, o bien son reconocibles en unidades en proceso de gramaticalización o ya plenamente gramaticalizadas -como en español, durante y mediante-.

\subsection{Participio de pasado}

El participio de pasado pasivo ${ }^{13}$ latino, por el contrario, sí tuvo continuación en las lenguas románicas. Ello, quizás, explique por qué los estudiosos de la sintaxis han dedicado menos tiempo a reflexionar sobre su estatuto latinizante. Cuando el participio funciona como un participium coniunctum, es decir, como complemento predicativo de una unidad con la que se relaciona anafórica o catafóricamente, su carácter latinizante ha pasado desapercibido, no ha sido destacado o, simplemente, no ha sido considerado por muchos estudiosos. Y, sin embargo, es lícito preguntarse si este empleo puede ponerse en relación con el frecuente uso del participio de que hacen gala tanto la prosa como la poesía latinas. En efecto, para la lengua italiana, autores como Segre (1963: 76), Pfister $(1978: 55,74,79)$ y Giovanardi (1993: 450) han relacionado el (ab)uso del participio, sobre todo en pasajes narrativos y en posición incidental (cf. §3.1.), con un tipo de construcción del discurso más elaborado, deudor del estilo narrativo de los historiadores clásicos y de la prosa argumentativa latina. ${ }^{14}$ En un reciente estudio (Del Rey 2016a), he podido comprobar que la prosa latinizante del siglo XV castellano es más dada al participium coniunctum que la prosa traducida de Alfonso X: mientras que este prefiere sustituir los participia coniuncta del texto latino por oraciones de relativo, Juan Rodríguez del Padrón respeta la naturaleza sintáctica del original, lo que redunda en una mayor literalidad estilística por parte del autor tardomedieval.

Por lo que respecta al uso del participio de pasado dentro de las construcciones absolutas, sí hay un mayor acuerdo en su naturaleza latinizante, ${ }^{15}$ habida cuenta de que la gran mayoría de los ablativos absolutos latinos se produce con este tipo de participio. ${ }^{16}$ No obstante, tampoco faltan las opiniones matizadas en este sentido. Por ejemplo, Nykrog (1957: 99) no cree que, sobre todo en francés antiguo, todas

las CA en -ant revisten estructuras de participio de presente, Mönch (apud Weerenbeck 1927) las consideraba gerundiales.

13 Aunque desde la perspectiva morfológica tradicional este tipo de participios, también en las lenguas romances, ha sido considerado pasivo, Fernández Leborans (1995: 369) apunta muy oportunamente que, en cuanto a la diátesis, solo "el participio de verbos transitivos es propiamente pasivo".

14 Cf., respecto del francés renacentista, Lardon y Thomine (2009: 371). La adscripción de las construcciones participiales a un registro elevado de lengua no se agota en la descripción del estilo literario de épocas pasadas, sino que para el italiano actual un autor como Loporcaro (2003: 241-242) puede afirmar que "PCCs [cf. n. 20] on the whole are rather learned constructions, more frequent in written than in spoken language".

15 Cf. un sucinto pero clarividente estado de la cuestión sobre las lenguas romances en Pountain (2010: 650-651). Menor controversia existe acerca de las CA nominales, cuya naturaleza culta y emuladora de las correspondientes CA latinas pocos estudiosos ponen hoy en duda (si bien, para el francés, desde Meyer-Lübke se cuestiona esta adscripción en algunos esquemas del tipo il est venu les mains vides, cf. Weerenbeck 1927: 148-149).

16 Las construcciones absolutas de participio (CAP) son consideradas herederas por vía culta del ablativo absoluto latino tanto en castellano (cf. Azofra 2009: 106) como en portugués (Da Silveira 1955: 203) y francés (Lardon y Thomine 1009: 331). 
las construcciones absolutas detenten un estatus culto, lo que prueba, según el autor, el abundante empleo de expresiones adverbiales en las que estaba implicado el sustantivo mente ya en latín vulgar, origen de las formas lexicalizadas en -ment en francés. ${ }^{17}$ Por su parte, Lorian (1973: 196), entiende que las CA son un tipo de esquema perteneciente al sistema del francés, es decir, forman parte de su base sintáctica patrimonial, ${ }^{18}$ si bien sí podría hablarse de una tendencia latinizante cristalizada en un mayor empleo de estas construcciones sobre todo en épocas de gran influencia de la literatura clásica en la francesa, como el Humanismo. ${ }^{19} \mathrm{Al}$ fin y al cabo, autores como Milani (2009: 169) afirman que las construcciones absolutas eran esquemas que podían estar representados en tipos de textos que no se situaran en el extremo de la distancia comunicativa, es decir, no eran ajenas a la liturgia y a otros tipos de manifestaciones lingüísticas que podrían considerarse afectadas por la lengua hablada o más relacionadas con ella. Que era una construcción "conosciuta e usata" (ibid.) lo demostraría ${ }^{20}$ el hecho de encontrar numerosos casos de nominativos y acusativos absolutos en los textos vulgares. ${ }^{21}$

\subsection{Gerundio}

Por lo que respecta a las estructuras gerundiales, sobre todo en lenguas como el español, el italiano y el portugués, en las que las formas de participio y de gerundio son

17 No obstante, hay que advertir que las construcciones en mente en latín vulgar y tardomedieval poco concuerdan con el concepto tradicional de "absoluto" (cf. §3.1). Si bien en ejemplos como el que aduce Nykrog (1957: 99), extraído de Catulo - obstinata mente-, en los que está implicado un adjetivo participial, puede llevarse a cabo un análisis sintáctico de sus constituyentes (núcleo verbal participial + nombre sujeto) idéntico al que se produce en el caso de las CA, las estructuras de adjetivo + mente carecen del carácter incidental propio de las construcciones de participio absoluto.

18 De opinión contraria son Pagliaro y Belardi (1963: 153), para quienes las CAP serían un elemento culto en francés mientras que en las otras lenguas romances, particularmente en italiano y en español, se trataría de formas heredadas -es decir, llegadas por vía patrimonial-. No obstante, para explicar esta idea los autores se refieren a su presencia en la literatura tradicionalmente relacionada con manifestaciones vulgares del latín, que, a fin de cuentas, no dejan de ser testimonios de la escrituralidad (cf. n. 1 y 3 ).

19 En este sentido, podríamos hablar, con Koller (1984: 114) de "quantitative Norminnovationen".

20 En sentido estricto, la existencia de nominativos y acusativos absolutos prueba, efectivamente, que tales construcciones eran conocidas por las personas letradas y, especialmente, por los semicultos (cf. Oesterreicher 1994) que, incurriendo en este tipo de transgresiones a la norma culta del latín, demostrarían que se trataba de estructuras propias de la escrituralidad, las cuales intentarían emular en su propio discurso con las limitaciones de su mediana competencia en el latín escrito.

21 Al referirnos al participio de pasado en este breve estado de la cuestión hemos querido distinguir el uso predicativo coniunctum del empleo en CA. Son escasos, sin embargo, los estudios que hacen una diferenciación explícita entre los dos tipos, lo que sin duda es necesario cuando se trata de esclarecer las características sintácticas de estructuras de esta índole. Loporcaro (2003: 205), en su bien documentado estudio sobre las construcciones participiales en italiano, sí parte de un denominador común para ambos tipos. A este hiperónimo descriptivo lo llama "participial circunstancial complement" (PCC), que define como "a reduced clause with the verb in participial form" y que engloba tanto las estructuras de participio absoluto (PA) como las de participio dependiente (PD), que se diferencian en virtud de la existencia (PD) o no (PA) de correferencia sintáctica (cf. §3.1), más específicamente de control sintáctico (p. 233), entre el sujeto de la oración participial y otros elementos de la oración principal. Loporcaro, sin embargo, se refiere en todo caso a estructuras "incidentales" (cf. §3.1); por nuestra parte, al intentar determinar el estatuto latinizante de estas construcciones, creemos que no conviene solo fijarse en este tipo de construcciones, pues la mera preferencia por una estructura de participio con complementos propios frente a una oración relativa puede ser reveladora del prurito culto o latinizante de una posibilidad idiomática en un contexto de variación dado (cf. Del Rey 2016a: 431-433). 
claramente diferenciadas ${ }^{22}$ ha sido más discutido su estatuto latinizante. El estudio de la prosa narrativa hace evidente que el gusto por la concatenación de gerundios, generalmente antepuestos a la oración principal, aunque no solo, es paradigmático de un tipo de lengua formal, ajena al hablado. ${ }^{23}$ No obstante, el uso predicativo-adverbial del gerundio, aisladamente considerado, no se asocia comúnmente a los discursos propios de la distancia, ${ }^{24}$ si bien por supuesto siempre habría que tener en cuenta el contexto de enunciación en que se inserta. ${ }^{25}$

Las CA de gerundio (CAG) ostentan, a priori, y en tanto que asimilables ${ }^{26}$ en muchos casos, sobre todo en textos traducidos, pero no solo en estos, a las estructuras de ablativo absoluto latinas, un carácter más culto que el que se deriva de un empleo predicativo de los mismos; sin embargo, si determinásemos, basándonos en una escala gradual, la naturaleza latinizante de las CA de participio y las de gerundio, las primeras serían colocadas por numerosos estudiosos en una posición más cercana al polo de máxima distancia comunicativa que las segundas (cf. Del Rey 2018). Con todo, en la bibliografía encontramos posturas, a veces, opuestas. Scavuzzo (1994: 472) contempla los gerundios absolutos explícitamente como latinismos sintácticos, así como para Pfister (1973: 230) tales construcciones presentan "zweifellos" una naturaleza latinizante. Lorian (1973: 196), sin embargo, defiende la tesis de que las CAG forman parte de la base patrimonial del francés. ${ }^{27}$ Una postura intermedia es

22 Tal diferencia no parece tan clara al considerar el origen del gerundio. Por ejemplo, en portugués, mientras que Da Silveira (1955: 201) sitúa el origen del gerundio romance en el participio de presente, Ali (1971: 146) lo hace derivar del gerundio latino en ablativo. Por lo demás, el abuso del período gerundial en el s. XIX ha sido considerado un galicismo sintáctico en la prosa portuguesa (cf. Cunha/Cintra 1984[1987]: 610).

23 Cf. Steele (1902: 419), Segre (1963: 309) y Serianni (1993: 460). Marazzini (1993: 248) incluye las construcciones de gerundio entre los rasgos que caracterizan la "sintassi fortemente latineggiante" del Boccaccio, mientras que Tesi (2001: 138) habla de ellas como rasgo típico de la prosa de Alberti. También para el italiano antiguo les concede estatuto latinizante Pfister (1978: 67). En el italiano actual también pueden caracterizarse como estructuras propias de la lengua escrita (cf. Menoni 1982: 44).

24 Albrecht (2016: 667) concede que son sobre todo las construcciones gerundiales del italiano y del español con valor causal las que concurren en registros más elevados.

25 La diversa interpretación variacional del gerundio coniunctum se explica por su versatilidad sintáctica y discursiva, que lo hace un elemento de junción frecuente y variado (Santiago 1979: 582-583) desde los inicios de las lenguas romances, si bien ya en latín medieval se percibe una progresiva diversificación de los usos del gerundio (cf. Gil 2004: 169). Mientras que la naturaleza gerundial de las formas en -ant en francés se pone de manifiesto cuando a estas las precede la preposición en, hay que destacar que la presencia de esta preposición no ha sido ajena a la historia de las otras lenguas romances (cf., por ejemplo, Da Silveira 1955: 168, 202, para el portugués; Vitale 1996: 359, para el italiano y Pato 2014 para el español). La variación morfológica del gerundio romance también se manifiesta en el hecho de contar con formas compuestas con los derivados de HABERE y *ESSERE. Tales formas son frecuentes en la prosa cronística e historiográfica y podrían ser consideradas elementos tradicionales discursivos propios de la lengua de la distancia. En el italiano, se ha discutido si las formas de gerundio compuesto preceden a las construcciones absolutas de participio sin concordancia y/o con objeto directo dentro de la cláusula-del tipo arrestatili, la polizia poté sedare il tumulto (cf. Loporcaro 2003: 226)-, hipótesis desechada por Menoni (1982: 10), que da prioridad a la evidencia de documentación escrita de la forma y que no cree que todas las construcciones absolutas de participio deban entenderse como cláusulas con omisión de una forma gerundial auxiliar (a diferencia de lo que opina Tekavčić 1980: II, §1181, p. 544-545). También en la historia del español se documentan las construcciones de participio de pasado con complementos directos, ya sean estos pronombres clíticos o no (cf. Keniston 1937: 100; Meilán 1991b: 283), estructuras en las que González Ollé (1995: 321) rechaza presuponer un fenómeno de elipsis del gerundio auxiliar.

26 Según Nykrog (1957: 101), las CAG, desde el antiguo y medio francés, están motivadas por las CAP. Especialmente frecuentes en este período son las CAG construidas sobre los verbos oür y voir.

27 Si bien, de acuerdo con la presentación del problema que ofrece De Roberto (2012: 71, n. 72), Rohlfs (1969: §726) también sería de la opinión de que el heredero directo del ablativo absoluto en italiano es el gerundio ab- 
la que adopta Durante $\left({ }^{5} 1981: 116\right)$ para el italiano, que habla de la CA de gerundio como una estructura "semidotta". En cualquier caso, somos de la opinión de que las construcciones gerundiales en español pueden ser estudiadas como esquemas, al menos, presuntamente latinizantes; en todo caso, no creemos que una investigación ocupada en la descripción y análisis de las estructuras absolutas deba dejar de lado las construcciones de gerundio, así como otras construcciones semiabsolutas o "incidentales" (cf. n. 30) representadas por estas formas no personales del verbo.

\section{Clasificación de los usos participiales y gerundiales y su reflejo en el corpus}

\subsection{Variedad de criterios para la caracterización sintáctica de las CA}

De lo dicho hasta ahora se desprende que la aparición de participios y gerundios en construcciones absolutas favorece su consideración como estructuras latinizantes. ${ }^{28}$ No obstante, tal apreciación puede convertirse en un problema desde el momento en que no está claro qué se debe entender por construcción absoluta. Las diferentes etiquetas terminológicas utilizadas para referirse a este tipo de cláusulas no han ayudado a esclarecer el problema de su definición. ${ }^{29}$ Incluso se ha llegado a poner en tela de juicio el carácter ‘absoluto' de las $\mathrm{CA}^{30}$ (cf. Narbona 1996: 469). Para poder responder a la pregunta de qué características poseen inequívocamente las CA, es necesario atender a la configuración sintáctica de las mismas. Existe acuerdo generalizado en que las construcciones absolutas representan cláusulas incidentales, ${ }^{31}$ exocéntricas $^{32}$ o accesorias, ${ }^{33}$ atribución en la que también pesa el criterio prosódico. ${ }^{34}$

soluto, lo cierto es que Rohlfs no llega afirmar tal cosa, ya que en este apartado se limita a decir que el desarrollo de las CAP del italiano se produce de forma independiente de las construcciones de ablativo absoluto latinas, a partir de construcciones de gerundio compuesto. En cualquier caso, se entiende que desde esta perspectiva las CAG sean percibidas como estructuras patrimoniales.

28 El estatuto latinizante de las CA en español ha derivado de su frecuente uso o de su uso predilecto en la lengua de los escritores humanistas, renacentistas y barrocos (cf. Lapesa 2000: 116, 471; Santiago 1979: 583-584; Pons Rodríguez 2015a: 290; Azofra 2011: 53). Para el francés se ha situado su apogeo en el siglo XVI (cf. Lorian 1973: 171; Lardon/Thomine 2009: 301). También en la lengua actual son propias de un registro elevado o culto (cf. Narbona 1996: 462) en todas las lenguas en que se presenta la estructura (cf. para el inglés Blatt 1957, quien no descarta, por lo demás, influencia sintáctica del francés en este caso). Tanto es así que Raible (1996: 126) caracteriza las CA como universales de la distancia.

29 Cf. Loporcaro (2003: 202) y las referencias ahí oportunamente incluidas.

30 Loporcaro (2003: 202-203) distingue dos significados básicos de 'absoluto'; el primero se corresponde con el sentido más común en la bibliografía que maneja el autor, es decir, aplicado a un participio, el adjetivo absoluto vendría a indicar que aparece "without a finite (auxiliary) verb", y funciona como hiperónimo: puede englobar tanto a los participios controlados sintácticamente por algún elemento de la oración principal como a los que no lo son (cf. n. 20). El segundo significado es menos habitual y denota una naturaleza hiponímica: se opone al participio dependiente, en el sentido de que no está controlado: absoluto y dependiente serían hipónimos respecto a la noción más abarcadora de complemento circunstancial participial.

31 La caracterización como incidental para este tipo de estructuras fue acuñada por Lapesa en un trabajo de 1975 (cf. Lapesa 2000: 259 y ss.) y retomada por Meilán (1991a: 289; 1991b: 274 y ss.), quien estudia en el apartado dedicado a las CA diferentes tipos de estructuras incidentales -nominales, adjetivales y adverbiales- (pp. 291299) que no demuestran un comportamiento idéntico al de las CA prototípicas.

32 Así en Müller-Lancé (1994: 33).

33 Caro (1976: 470).

34 No de otro modo habría que entender el "facteur rythmique" al que se refiere Lorian (1973: 206). 
Esta caracterización se postula como el leitmotiv de las diferentes definiciones propuestas en la bibliografía consultada y la que vincula las CA de participio y gerundio prototípicas con las CAP y las CAG precedidas de preposición ${ }^{35}$-de acuerdo con el precedente o modelo latino ab urbe condita-, las CA nominales puras, ${ }^{36}$ las construcciones semiabsolutas ${ }^{37}$ y otras estructuras menos habituales, pero también consideradas propias de la escrituralidad, como las construcciones de acusativo griego ${ }^{38}$ Las cuestiones más controvertidas en lo que atañe a la caracterización de las CAP y de las CAG, las que de forma preferente nos interesan en este artículo, giran en torno a su naturaleza informativa (a), su estructura interna (b) y sus vínculos de correferencialidad con elementos de la oración regente (c). En el presente apartado nos centraremos con prioridad en estos dos últimos puntos.

a) A propósito del estatus informativo ${ }^{39}$ que poseen en el discurso las CA, muchos estudiosos han destacado su característica disposición bimembre que configura una particular fisonomía textual habitual, por ejemplo, en las obras historiográficas, ricas en la acumulación de este tipo de estructuras. ${ }^{40}$ No hay acuerdo, sin embargo, acerca de la propia naturaleza informativa de las CA. Refiriéndose al latín, Ramat (1994) atribuye a estas estructuras un carácter prototípicamente temático, que explica su frecuente posicionamiento a la izquierda de la oración regente (OR); de esta forma, las CA se entienden como valedoras de la información conocida que funciona como transición entre el fragmento anterior y la información nueva que aporta la OR. El valor temático de las CA es también defendido por De Roberto (2012: 234), incluso en los casos en que la cláusula aparece pospuesta a la oración principal. Por el contrario, Müller-Lancé (1994: 370) concluye que la mayoría de las CA por él analizadas revela una naturaleza remática, desde el momento en que aportan al discurso información no conocida o no mencionada antes en el discurso. Quizás la diferente opinión de estos autores no tenga que ver con el verdadero estatuto informacional de las CA sino con la propia definición de tema y rema, sobre la que no hay acuerdo en la bibliografía. ${ }^{41}$

b) En lo que atañe a su estructura interna, la construcción absoluta prototípica es la que combina un elemento nominal o pronominal con un participio o gerundio

35 Un tanto descuidado ha sido su tratamiento en español (cf. Meilán 1991b: 281). Para el francés, cf. Lorian 1973: 210). En italiano, De Roberto (2012) las denomina "CA al participio aumentate".

36 Cf. entre otros (Lapesa 2000: 113-115) y Meilán (1991b: 283) para el español y De Roberto (2012: 315-370) para el italiano.

37 Para Meilán (1991b: 288-291), construcciones semiabsolutas son aquellas en que falta el sujeto del participio o del gerundio, quedando de este modo solo la forma no personal del verbo en función incidental. En un sentido totalmente diferente acuñó el término de semi-absolu Lorian (1968: 1272; 1973: 209), que lo utiliza para referirse a CA en las que están implicadas verbos intransitivos, concretamente inacusativos - del tipo la nuit venue, tous s'endormirent-.

38 Cf. Keniston (1937: 236), Lapesa (2000: 103-105) y De Roberto (2012: 295: 313).

39 Desde una perspectiva diacrónica, Combettes (2003) considera fundamental estudiar la evolución de las funciones informativas que desempeñan las CA, lo que sin duda motivó su empleo en determinadas posiciones de la oración y contribuyó al desarrollo de su carácter incidental desde estructuras predicativas.

40 Cf. Elvira (2004: 454). Müller-Lancé (1994: 371) destaca que las absolutas son construcciones muy económicas informativamente.

41 No es este el lugar para discutir la cuestión. Remitimos a López Serena y Borreguero (2011: 197-198), quienes apuntan, entre otras interesantes precisiones, que el tema no se identifica solo con la información conocida sino que "contiene preferentemente una información que es de fácil acceso cognitivo para el receptor, bien porque guarde relación con el contexto comunicativo, bien porque haya sido introducida en el cotexto inmediato, bien porque forme parte del conocimiento del mundo del lector". 
( $u$ otro nombre en el caso de las construcciones nominales puras), del que aquel funcionaría como sujeto. Ambos elementos establecerían entre sí una relación de interdependencia (Gutiérrez Ordóñez 1978: 310). La diferencia de pareceres entre los estudiosos de estas estructuras estriba en la aceptación o no de que la presencia de sujeto en la cláusula absoluta sea condición necesaria para caracterizar la estructura como tal. Gutiérrez Ordóñez (1986: 158) afirma que "únicamente en circunstancias muy excepcionales" puede faltar el sintagma nominal en la CA. Garrido Medina (1996: 310) y Suárez Fernández (1996) no aceptan como CA aquellas en las que falta algún miembro de la construcción bimembre ${ }^{42}$ En la minuciosa caracterización de De Roberto (2012) para el italiano, las CA propiamente dichas son solo aquellas en las que el sujeto está explícito; por su parte, Müller- Lancé (1994: 30), en su estudio sobre las CA en latín y francés, admite que el sujeto de la cláusula absoluta puede no estar explícito ${ }^{43}$ siempre que sea reconstruible a partir del contexto y que sea diferente del sujeto de la oración regente, otro aspecto, este, no exento de problemas y desacuerdos entre los investigadores, al que aludimos en el siguiente párrafo. ${ }^{44}$

c) Al describir su estructura interna, Ernout y Thomas (1953[1989]: 104) advierten que normalmente el elemento nominal o pronominal de la frase participial de la CA en latín no es recuperado ni como sujeto ni como complemento de ningún tipo en la oración principal. Si bien es cierto que en latín clásico la mayoría de los ablativos absolutos cumple estas restricciones, no dejan de encontrarse casos en los que existe correferencia entre la parte nominal de la CA y alguna unidad sintáctica de la principal, como atestiguan Hoff (1989) y Milani (2009) a propósito de los Commentarii belli Gallici de César. ${ }^{45}$ Para Hoff, y para otros muchos autores que se han ocupado de esta cuestión, desde una perspectiva algo menos encorsetada, el requisito fundamental que debe cumplir una construcción absoluta es el de que el sujeto de la OR y el de la oración de participio no sean correferentes. Mientras que las restricciones extremas de correferencia sintáctica han sido superadas por los estudiosos ${ }^{46}$ las que se refieren a la correferencia entre los sujetos todavía perviven. De este modo, encontramos en la bibliografía una oposición de opiniones entre los autores para los que la correferencia entre el sujeto de la OR y el de la CA no es un impedimento para considerar la estructura como tal ${ }^{47}$ y aquellos para los que la no correferencia de sujetos es un requisito imprescindible para hablar de la cláusula incidental como

42 "[E]ntendemos como característica general de las mismas [CA] su constitución bimembre, lo que significa que quedan excluidas de esta consideración las estructuras en las que alguno de sus miembros es recuperable a partir de cierto constituyente de la predicación principal” (Suárez Fernández 1996: 585). Cf. también Reese (1991: 31).

43 De la misma opinión son Keniston (1937: 555) y Lorian (1973: 205-206).

44 La exclusión del carácter absoluto en muchas estructuras romances sin sujeto explícito podría tacharse cuanto menos de severa, pues, si bien en época republicana tal circunstancia era excepcional, no es para nada infrecuente en Cicerón y en Tácito (cf. Ernout-Thomas 1953[1989]: 105).

45 Cf. "obsidibus imperatis centum hos Haeduis custodiendos tradit” (César, Commentarii belli Gallici, VI, 4, 3, p. 92, 1. 13, apud [LLT]).

46 No obstante, sigue teniendo vigencia, por ejemplo, en Hallebeek (1998: 191), aunque algunos de los ejemplos que ofrece denotan algún tipo de anáfora asociativa entre el sujeto de la CA y algún elemento de la OR.

47 De esta opinión son Keniston (1937: 51), Caro (1976), Gutiérrez Ordóñez (1986: 155), Meilán (1991b: 277), Leborans (1995: 360), Marques Barreiro (1998: 23) y Elvira (2004: 456), para quien, de hecho, la correferencialidad es lo más frecuente en castellano ya en época medieval (Elvira 1996: 257). Para el latín, frente a lo que viene siendo habitual, la definición abierta de Coleman (1989: 354) parece contemplar igualmente esta posibilidad. 
absoluta. ${ }^{48}$ El criterio de correferencialidad es fundamental en la clasificación de De Roberto (2012), quien, en función de ella, distingue, para el italiano, entre:

1. CA propiamente dichas, es decir, aquellas que tienen un sujeto explícito no correferente con el sujeto de la principal: Venuto il seguente giorno, Tarolfo andò alla donna, e disse [...] (Boccaccio, Filocolo, apud De Roberto 2012: 173).

2. Construcciones pseudoabsolutas, que, sobre todo en el caso de los gerundios, pueden presentar tres variantes:

2.1. Sujeto explícito en la CA correferente con el de la regente: Vedendo il re che i fortunosi casi aveano conceduta la vittoria alle sue armi, in se medesimo molto si rallegrò (Boccaccio, Filocolo, apud De Roberto 2012: 287).

2.2. Sujeto no explícito impersonal en la CA y por lo tanto no correferente con el de la principal: Tornando al tondo della terra, dice la scrittura de' filosofi che [...] (Pulci, Libro, apud De Roberto 2012: 292).

2.3. Sujeto no explícito en la construcción de gerundio pero no impersonal sino reconstruible por el cotexto: Traiano fue imperadore molto iusto. Ed essendo un die salito a cavallo per andare alla battaglia co la cavalleria sua, una femina vedova venne (Fiori e vita, apud De Roberto 2012: 293). Ese tipo se encuentra estigmatizado estilísticamente en el italiano contemporáneo.

3. Adjuntos libres, ${ }^{49}$ esto es, construcciones de participio o de gerundio incidentales o exocéntricas que no tienen sujeto propio y son correferentes con el sujeto de la OR: Guardando la televisione, Maria mangiò un gelato (apud De Roberto 2012: 92).

Sorprende que el aspecto de la correferencialidad ahorme tan decisivamente el exhaustivo estudio de De Roberto (2012; cf. Del Rey 2016c). No obstante, tras analizar numerosos ejemplos de épocas pasadas, la misma autora reconoce que, en muchos casos, la distinción entre adjunto libre (AL) y CA no es pertinente en virtud de la similar función que ambas estructuras cumplen en el discurso (ibid.: 203).

Por lo que respecta al punto b), asumimos aquí la posibilidad de que una CA pueda estar constituida por un núcleo participial o gerundial sin sujeto expreso. Igualmente, en este trabajo no consideramos el requisito de acorreferencialidad entre los sujetos de la CA y la OR como decisivo para definir las estructuras de participio y/o de gerundio como absolutas. Tendremos en cuenta, pues, las estructuras con sujeto propio, independientemente de sus vínculos sintácticos con otras unidades de la $\mathrm{OR}, \mathrm{y}$, por lo demás, no nos abstendremos de incluir en el análisis algunos casos fronterizos que, en nuestra opinión, deben ser también representados en un trabajo que se proponga estudiar este tipo de cláusulas como estructuras que comparten un estatuto variacional similar, de ahí que no releguemos en el análisis a los AL. A continuación nos referiremos a distintos tipos de construcciones participiales y gerundiales documentados en el corpus para, seguidamente, dar muestra de los problemas que una clasificación sintáctica rígida representa a la hora de procurar una taxonomía cerrada.

\footnotetext{
48 Este requisito es fundamental en la concepción de Rosen (1981[1988], apud Loporcaro 2003: 204) y es el adoptado para su análisis por Müller-Lancé (1994). Cf. también Serianni (1989[2010]) y Muñío (1995: 239), que definen las CA para el italiano y para el español, respectivamente, a partir de esta característica. De idéntica opinión son Reese (1991: 33) para el español y Hricsina (2015: 270) para el portugués.

49 Toma la designación de Stump (1985) y Kartmann (1991). Cf. asimismo Hantson (1992).
} 


\subsection{Aplicación de una tipología y problemas derivados}

Numerosos ejemplos en el corpus atestiguan la concurrencia de las CA que De Roberto (2012) y otros autores consideran prototípicas, es decir, aquellas cuyos sujetos no son correferentes a los de las OR. ${ }^{50}$ Por supuesto, las relaciones de correferencia se dan con otros elementos de la CA, como observamos en (1), donde el clítico de OD (-le) se identifica con el sujeto de la OR. En (2), en cambio, la ligazón referencial se basa en la anáfora asociativa que vincula las partes del fruto al que alude la metáfora empleada:

(1) a. Thersites, dum sceptro percussus fundit lachrymas, risui est exercitui, suo malo discens tacere, qui loqui non didicerat ( $L i$, p. 35, 1. 320-322).

b. solo Thersites con su mal aprendía a callar, pues no quería aprender a hablar, y assí hiriéndole el rey con el ceptro, lloró y hizo reír a todos (Le, p. 23).

(2) a. Magis sapiet, magis pascet vnius versiculi meditatio, si rupta siliqua medullam erueris (Ench, p. 19, § 19).

b. Mejor te sabrá y mejor provecho te terná el entendimiento de un versico, si, quebrada la cáscara, sacares el meollo de dentro (Enqu, p. 139).

Más numerosas son las estructuras que De Roberto (2012) denomina pseudoabsolutas, en los tres supuestos estudiados por la autora:

a) cuando existe correferencia de sujeto pero este aparece adjunto al gerundio (3) o al participio $^{51}(4)$ :

(3) assi ternemos más de verdad puesta toda nuestra confiança en las que dél recebimos, y viendo Dios esta nuestra fe y que en sólo él confiamos, luego corresponderá a ella (Enqu, p. 147).

(4) a. Postremo Dominus a matre consultus respondit (Ench, p. 40, § 4).

b. consultado Dios por la madre qué sucedería destos sus dos hijos, respondió [...] (Enqu, p. 178).

b) cuando el gerundio carece de sujeto por tratarse de una expresión impersonal, de manera que la correferencia con el sujeto de la OR no se $\operatorname{produce}^{52}(5)$ :

50 Los porcentajes para este tipo de CA son los siguientes: 18,18\% para la traducción del Enchiridion, 18,41\% para la traducción de la Lingua, 34,85\% para la Silva y 36,84\% para los Diálogos. Mientras que en las obras de Pérez de Chinchón las CAG sin correferencia entre el sujeto de esta y el de la oración principal son más numerosos que las CAP, en el Arcediano del Alcor se percibe una ligera tendencia hacia esta última estructura para este tipo de CA (documentamos 13 CAG y 13 CAP en la traducción del Enchiridion, pero 26 CAP frente a 20 CAG en la Silva).

51 Este subtipo representa el 4,89\% en la traducción del Enchiridion, el 5,44\% en la de la Lingua, el 3,79\% en la Silva y un porcentaje algo más elevado, un $11,84 \%$ en los Diálogos. Ejemplos como los de (4), en los que está implicado un participio, son raros. El hecho de que se dé un mayor porcentaje de construcciones absolutas y pseudoabsolutas en las obras no traducidas que en las traducidas puede ser exponente de la tendencia a la interferencia negativa de divergencia que se percibe frecuentemente en los textos traducidos del latín desde la Edad Media (cf. Del Rey 2016b; 2017).

$52 \quad 6,29 \%$ en la traducción del Enchiridion, 3,76\% en la de la Lingua, 9,09\% en la Silva y 3,95\% en los Diálogos. No se encuentran soluciones de este tipo para las construcciones participiales. 
(5) a. garrulitas facit, vt quod suapte natura suauissimum est, si quis sicut oportet vtatur, id summam adferat vitae molestiam ( $L i$, p. 43, 1. 555-557).

b. esta parlería haze que lo que de sí es muy suave, usando bien dello, parezca enojoso y pesado a nuestra vida (Le, p. 31).

c) en los numerosos casos en que el gerundio aparece sin sujeto pero este es reconstruible a partir del co(n)texto y es diferente del sujeto de la oración principal (6); aunque en menor medida, esta circunstancia también es aplicable a las construcciones pseudoabsolutas de participio $^{53}$ (7):

(6) dice que el Rey Don Sancho su padre la reedificó y pobló, habiendo estado por 300 años desolada (Si, p. 113).

(7) manda que el Concejo de Palencia haga homenaje al Obispo y llegado a la iglesia, luego le despojan de todos aquellos atavíos ( $\mathrm{Si}$, p. 78).

Sin embargo, los casos más frecuentes de construcciones "incidentales" los constituyen los esquemas de concordancia predicativa -adjuntos libres (AL), cf. §3.1-, especialmente frecuentes en el caso de los gerundios, como el del ejemplo (8). ${ }^{54} \mathrm{Tal}$ como puede colegirse de este ejemplo, los adjuntos libres gerundiales corresponden en los textos traducidos muy frecuentemente a los participios de presente latinos. Menos frecuentes son los adjuntos libres constituidos por participios de pasado (9) -participia coniuncta-, pues estos presentan como restricción sintáctica el hecho de ser verbos inacusativos (volver, regresar, llegar):

(8) a. Fur quoniam frustra tentauerat elabi per fenestras vicinis arcentibus, decreuit exire per ostium credens futurum vt illic falleret ( $\mathrm{Li}, \mathrm{p}$. 77, 1. 663-664).

b. Él, como no pudiesse salir por las ventanas porque los vezinos no le viessen, determinó salir por la puerta, creyendo que también los engañaría (Le, p. 71).

(9) a. Mox igitur adit primores et exposita fabula ciuitatem ac senatum inani trepidatione liberat. Deinde domum reuersus expostulat cum vxore ( $L i$, p. 64, 1. 237-238).

b. Así que fuésse luego a los principales y díxoles lo que passava y que no tuviessen miedo, pues la cosa era fingida; y buelto a su casa, empeçó de reñir con su muger (Le, p. 55).

Las pautas adoptadas por los diferentes investigadores en la clasificación de las CA no están, por supuesto, exentas de problemas. Sobre todo cuando se trata de textos antiguos, los criterios de edición adoptados, y muy particularmente el establecimiento de las pausas en el interior de los párrafos, representadas a manera de comas y puntos en el medio gráfico, pueden condicionar la determinación de una construcción como CA o como AL. Así ocurre en (10) y (11), ejemplos en los que, de acuerdo con la convención transcripción asumida por el editor en cada caso, las formas no

13,99\% en la traducción del Enchiridion, 5,86\% en la de la Lingua, 2,94\% en la Silva y 6,58\% en los Diálogos.

54 Así lo evidencian los porcentajes por tipos calculados en cada obra: por lo que respecta los textos traducidos, los casos los AL alcanzan una cifra superior al 50\% (56,64\% en la traducción del Enchiridion, 66,52\% en la de la Lingua); inferior en el caso de las obras originales, aunque también los porcentajes son considerables: $49,23 \%$ en la Silva y $40,79 \%$ en los Diálogos. 
personales del verbo, gerundio y participio respectivamente, quedan desligadas de su posible sujeto al que, siendo este el mismo que el de la oración regente, se prefiere interpretar como el agente explícito de la acción expresada en esta:

(10) a. Hunc quum Phocion videret [...] inquit ( $L i$, p. $70,1.445 / 448)$.

a. Pues viendo esto, Phoción dixo (Le, p. 63).

(11) a. Heracletus quum in seditione rogaretur a ciuibus, vt pro concione suaderet concordiam, ascendit pulpitum ( $L i$, p. 56, 1. 965-966).

b. Herácleto, rogado por sus ciudadanos que juntando el pueblo les persuadiesse paz, porque todos estavan alborotados con vandos, subió en un púlpito [...] (Le, p. 45).

Hemos visto que el criterio de correferencialidad entre el sujeto de la cláusula absoluta y el de la OR y el criterio de copresencia de sujeto explícito y forma no personal dentro de la CA son esenciales en varias de las taxonomías elaboradas sobre este tipo de construcciones. Sin embargo, considerados desde una perspectiva estilística, fundamental por lo que respecta a la determinación de su carácter culto o latinizante, tales criterios chocan con la percepción de homogeneidad relativa a la propia naturaleza discursiva de unidades que se comportan en el texto de idéntico modo a pesar de no compartir las características sintácticas que suelen atribuírseles como definitorias a las construcciones absolutas y pseudoabsolutas. Así, por ejemplo, los diferentes argumentos verbales que exigen en cada caso creer y parecer, es decir (S) + V + OD (oración completiva) frente a OI $+\mathrm{V}+\mathrm{S}$ (oración completiva), no impide considerar semántica y discursivamente equivalentes las oraciones creo que el paquete ya ha llegado y me parece que el paquete ya ha llegado. De este modo, que la diferencia entre una oración como la de (12), que incorpora una estructura de gerundio que los analistas considerarían CA por constar de un sujeto no correferente al de la oración principal, y otra oración, recreada por mí, como la de (12'), donde solo se hablaría de AL simplemente por el hecho de que el sujeto reconstruible del gerundio es correferente con el de la OR, no es, en realidad, significativa en términos estilísticos y en lo que atañe a la configuración textual:

(12) a. Nos [...] praedicamus CHRISTVM crucifixum, Iudaeis quidem scandalum, gentibus autem stultitiam (Ench, p. 24, §2).

b. Nosotros predicamos a Jesu Christo crucificado, cosa de que los judíos se escandalizan [...], y de que los gentiles por otra parte se burlan, pareciéndoles que es contra su saber (Enqu, p. 151).

(12') y de que los gentiles por otra parte se burlan, creyendo que es contra su saber.

La excesiva relevancia concedida al aspecto de la correferencialidad entre los sujetos de la OR y la CA supone, por lo demás, que la ciega aceptación del criterio de acorreferencialidad en este sentido nos lleve a admitir casos de interpretación ambigua, como el de (13), ejemplo en el que existe correferencialidad semántica entre los sujetos, pero no morfológica, ya que el verbo de la principal asume marca de persona plural como consecuencia de la concordancia ad sensum que motiva el significado colectivo del sujeto adjunto del gerundio en la cláusula absoluta: ${ }^{55}$

55 CA y falta de concordancia con toda probabilidad inspiradas en el TF, aunque aquí el cambio de sujeto entre la CA y la OR (concursu vs. plerique) no produce ninguna anomalía sintáctica. 
(13) a. Facto igitur populi concursu plerique disputabant, quid sibi vellet ea lagena ( $\mathrm{Li}$, p. 67, 1.673-674).

b. Allegándose, pues, el pueblo, disputavan que a qué propósito pudo estar allí aquel barril (Le, p. 71).

En fin, en los períodos, muy frecuentes en las épocas medieval (cf. Elvira 1996: 253) y clásica (Cano Aguilar 1991: 67), tanto en la prosa narrativa como en la expositiva o argumentativa, en los que se coordinan o yuxtaponen dos o más secuencias de gerundio, generalmente antepuestas a la oración regente, sucede alguna vez que la primera de las cláusulas coordinadas integra el participio o el gerundio con su sujeto, mientras que el resto de formas personales que se sucede en el/los siguiente(s) período(s) aparece exento. También en estos casos parecería demasiado encorsetada la decisión de considerar solo el primer esquema una CA o pseudoabsoluta, pues la uniformidad de la disposición textual es homogénea en la serie coordinada o yuxtapuesta independientemente de que el sujeto de la forma no personal aparezca solamente al inicio del macroperíodo (14):

(14) a. Itaque quum rhetor quispiam encomium Herculis, quod ingenti studio composuerat, recitare vellet apud Antalcidam Lacedaemoniorum ducem, tanquam initurus amplissimam gratiam, ille non passus est ( $L i$, pp. 41-42, 1. 508-511).

b. Y queriendo un día un rethórico hazer un sermón en alabança de Hércules, pensando por esto ganar mucho favor con Antálcidas, capitán de los lacedemonios, el mesmo Antálcidas no se lo consintió (Le, p. 29).

\section{Conclusiones y tarea pendiente}

El presente trabajo ha llamado la atención sobre la necesidad de considerar las estructuras participiales y gerundiales en conjunto, es decir, atendiendo a todas sus posibilidades sintácticas de aparición, para poder determinar así su estatuto latinizante. Si bien se ha dedicado una mayor atención al problema de la caracterización de las construcciones absolutas, por ser estas las que más habitualmente se integran en la nómina de estructuras latinizantes, hemos insistido en que determinados usos predicativos, incluso no incidentales, del participio y del gerundio pueden corresponder con estrategias, si no latinizantes, al menos sí típicas de registros formales, especialmente frecuentes en determinadas tradiciones discursivas propias de la escrituralidad, desde la Edad Media hasta nuestros días.

A propósito de las diferencias existentes entre los diversos tipos de construcciones de gerundio y participio, podríamos establecer diferentes grados en la caracterización variacional de estructuras participiales y gerundiales a lo largo del continuum entre oralidad y escrituralidad concepcionales (cf. Koch y Oesterreicher 1990[2007]): una CA de participio de presente se situaría en un extremo del continuum, mientras que una estructura predicativa, concertada con el sujeto, tal vez sin abandonar el ámbito de la escrituralidad, según el contexto, ocuparía un lugar más lejano al extremo del continuum. ${ }^{56}$

Remito a mi artículo (Del Rey 2018) para una explicación más pormenorizada de esta idea con un gráfico que distribuye a lo largo del continuum las distintas unidades participiales y gerundiales que he analizado en este trabajo. 
Por lo que respecta específicamente a las construcciones absolutas, hemos abogado por una concepción abarcadora, no ahormada por el criterio estricto de correferencialidad sintáctica, a propósito de la cual hemos traído a colación ejemplos controvertidos y casos fronterizos que ponen en duda la rentabilidad de algunos de los criterios adoptados por los lingüistas. También hemos discutido si la coaparición del sujeto dentro de la construcción participial o gerundial debe postularse como requisito indispensable para la caracterización de la estructura como absoluta. A fin de cuentas, desde una perspectiva estilística, el criterio de incidentalidad, de índole prosódica y/o gráfica, según los casos, que es fundamental en todas las descripciones de las CA, parece prevalecer sobre otros criterios sintácticos. Desde una perspectiva discursivo-tradicional (cf. Winter-Froemel/López Serena/Octavio de Toledo/FrankJob 2015), la copresencia de CA prototípicas, construcciones pseudoabsolutas y adjuntos libres perfila de forma homogénea la naturaleza discursiva de distintos tipos de textos, propios de la escrituralidad, como la crónica y el ensayo, y les confiere un perfil concepcional característico.

Naturalmente, sería posible establecer diferencias más finas en lo que atañe a los diferentes tipos de estructuras participiales y gerundiales de acuerdo con el tipo de texto en el que concurren y con el estatuto variacional que detentan en cada caso. Para conseguir delimitar esas diferencias, sería necesario un análisis exhaustivo de las características morfológicas (género y número de los participios, forma simple o compuesta en el caso de los gerundios), sintácticas (posición de los elementos dentro de la CA, posición de la CA dentro de la oración, función sintáctica de las unidades adyacentes a la CA), semánticas (tipo de verbo implicado, tipo de relación significativa que establece la $\mathrm{CA}$ respecto de la $\mathrm{OR}$ ) y discursivas (carácter remático o temático de la CA, relevancia informativa, papel argumentativo, etc.). Confiamos en que dicho análisis sea realizado en futuros estudios con reveladora información sobre el polivalente comportamiento de las construcciones de participio y de gerundio con base a otros corpus, a otras épocas y a otras lenguas romances.

\section{Fuentes documentales}

Desiderii Erasmi Roterodami Enchiridion militis christiani saluberrimis praeceptis refertum, Halae, anno MDCCXXIV.

Lingua Erasmi Roterodami. En Opera omnia Desiderii Erasmi Roterodami, Ordinis quarti tomus primus, edición de Jan Hendrik Waszink, Amsterdam: North-Holland Publishing Company.

Alonso Fernández de Madrid. Silva palentina, edición de Matías Vielva Ramos. Palencia: Excma. Diputación Provincial, 1932.

Bernardo Pérez de Chinchón. Dialogos christianos contra la secta Mahometana y contra la pertinacia de los judios, Valencia, Francisco Díaz Romano, 1535.

Alonso Fernández de Madrid. El Enchiridion o Manual del caballero cristiano, edición de Dámaso Alonso. Madrid: Consejo Superior de Investigaciones Científicas, 1971.

Bernardo Pérez de Chinchón. La Lengua de Erasmo nuevamente romançada por muy elegante estilo, edición de Dorothy Severin. Madrid: Anejo XXXI del Boletín de la Real Academia Española, 1975. 


\section{Referencias bibliográficas}

Albrecht, Jörn (2016): “L'apport des traducteurs à la «relatinisation» des langues romanes", en Manuel de traductologie, Jörn Albrecht y René Métrich (eds.), pp. 657-670. Berlin/ Boston: De Gruyter.

Ali, Manuel Said (1971): Gramática Histórica da Língua Portuguêsa. Rio de Janeiro: Livraria Acadêmica.

Azofra, Elena (2006): "Problemas de sintaxis y traducción. El caso del participio de presente en español”, Epos XXII:67-80.

Azofra, Elena (2011): "La historia de la partícula aparte en español”, Revue Romane 46/1:4268.

Blatt, Franz (1957): Latin Influence on European Syntax, Classica et mediaevalia XVIII:133-178.

Borreguero Zuloaga, Margarita y Araceli López Serena (2011): "Marcadores discursivos, valores semánticos y articulación informativa del texto: el peligro del enfoque lexicocentrista", en Marcadores del discurso: de la descripción a la definición, Heidi Aschenberg y Óscar Loureda Lamas (eds.), pp. 169-210. Madrid/Frankfurt am Main: Iberoamericana/ Vervuert.

Brunot, Ferdinand ( $\left({ }^{4} 1933\right)$ : Histoire de la langue française des origines à 1900. Tome I: De l'époque latine à la Renaissance. Paris: Armand Colin.

Campos Souto, Mar (2001): "So la sonbra de los árvoles fazientes verano: el participio de presente en una traducción castellana cuatrocentista", Moenia 7:371-391.

Cano Aguilar, Rafael (1991): "Sintaxis oracional y construcción del texto en la prosa española del Siglo de Oro", Philologia Hispalensis VI:45-67.

Caro, Miguel Antonio (1976): Tratado del participio. Bogotá: Anales de la Universidad.

Coleman, Robert (1989): "The rise and fall of absolute constructions: A Latin case history", en Subordination and Other Topics in Latin. Proceedings of the Third Colloquium on Latin Linguistics (Bologna, 1-5 Aprile 1985), Gualtiero Calboli (ed.), pp. 353-374. Amsterdam/Philadelphia: John Benjamins.

Combettes, Bernard (2003): "L'évolution de la forme en -ant: aspects syntaxiques et textuels", Langages 37/149:6-24.

Cunha, Celso y Luís F. Lindley Cintra (1984[1987]): Nova gramática do português contemporâneo. Lisboa: Costa.

Da Silveira Bueno, Francisco (1955): La Formação Histórica da Língua Portuguêsa. Rio de Janeiro: Livraria Acadêmica.

De Cesare, Anna Maria y Giovanna Brianti (2016): “Constructions «impersonnelles» vs constructions «personnelles» comme problème de traduction", en Manuel de traductologie, Jörn Albrecht y René Métrich (eds.), pp. 256-274. Berlin/Boston: De Gruyter.

De Roberto, Elisa (2012): Le costruzioni assolute nella storia dell'italiano. Napoli: Loffredo.

Del Rey Quesada, Santiago (2015): Diálogo y traducción. Los Coloquios erasmianos en la Castilla del s. XVI. Tübingen: Narr (ScriptOralia 140).

Del Rey Quesada, Santiago (2016a): "Ocho tipos de lengua, cara a cara: las traducciones de la epístola ovidiana de Dido a Eneas en la Edad Media y el Siglo de Oro", en El español a través del tiempo. Estudios ofrecidos a Rafael Cano Aguilar, Araceli López Serena, Antonio Narbona Jiménez y Santiago del Rey Quesada (dirs.), tomo I, pp. 415-439. Sevilla: Editorial Universidad de Sevilla.

Del Rey Quesada, Santiago (2016b): "Interferencia latín-romance en Alfonso X: la traducción como pretexto de la elaboración sintáctica”, La corónica 44.2:75-109. 
Del Rey Quesada, Santiago (2016c): “De Roberto, Elisa, Le costruzioni assolute nella storia dell'italiano, Napoli, Loffredo (2012), 415 pp.”, Cuadernos de Filología Italiana 26:299306.

Del Rey Quesada, Santiago (2017): “(Anti-)Latinate Syntax in Renaissance Dialogue: Romance Translations of Erasmus's Uxor Mempsigamos", Zeitschrift für romanische Philologie 133/3:673-708.

Del Rey Quesada, Santiago (2018): "El De senectute de Cicerón en romance (ss. XIV-XVI): un estudio sintáctico contrastivo", Anuari de Filologia. Estudis de Lingüística 8:21-56.

Durante, Marcello ( $\left.{ }^{5} 1981\right)$ : Dal latino all 'italiano moderno, Bologna: Zanichelli.

Elvira, Javier (1996): “Construcciones de gerundio con sujeto en la prosa histórica alfonsí”, en Actas del III Congreso Internacional de Historia de la Lengua Española: Salamanca, 22-27 de noviembre de 1993, Alegría Alonso González (coord.), tomo I, pp. 257-267. Madrid: Arco/Libros

Elvira, Javier (2004): "Los caracteres de la lengua: gramática de los paradigmas y de la construcción sintáctica del discurso", en Historia de la lengua española, Rafael Cano Aguilar (dir.), pp. 449-472. Barcelona. Barcelona: Ariel.

Ernout, Alfred y François Thomas (1953[1989]): Syntaxe latine. Paris: Klincksieck.

Fernández Leborans, M. ${ }^{a}$ Jesús (1995): "Sobre construcciones absolutas", Revista Española de Lingüistica 25/2: 365-395.

Garrido Medina, Joaquín (1996): “Gerundio especificativo y de posterioridad en español: corrección y relaciones sintácticas”, en Actas del III Congreso Internacional de Historia de la Lengua Española: Salamanca, 22-27 de noviembre de 1993, Alegría Alonso González (coord.), tomo I, pp. 309-324. Madrid: Arco/Libros.

Gil, Juan (2004): "El latín tardío y medieval (siglos VI-XIII)", en Historia de la lengua española, Rafael Cano Aguilar (dir.), pp. 149-182. Barcelona: Ariel.

Gil, Juan (2012): "Latinismos sintácticos en la traducción de la Eneida de Don Enrique de Villena”, Boletín de la Real Academia Española XCII/CCCVI:179-211.

Giovanardi, Claudio (1994): "Il bilinguismo italiano-latino del medioevo e del Rinascimento", en Storia della lingua italiana. Volume secondo: Scritto e parlato, Luca Serianni y Pietro Trifone (eds.), pp. 435-467. Torino: Einaudi.

González Ollé, Francisco (1995): “Origen del participio pasado con complemento directo", Revista de Filología Española LXXV/3-4:319-331.

Greco, Paolo (2016): "Il participio presente dipendente da verbi di percezione diretta nel medioevo latino (e romanzo)", Aemilianense IV:367-401.

Gutiérrez Ordóñez, Salvador (1978): “Construcciones atributivas absolutas”, Verba 5:305314.

Gutiérrez Ordóñez, Salvador (1986): Variaciones sobre la atribución. León: Universidad de León.

Hallebeek, Jos (1998): “Sintaxis y uso del gerundio en español actual”, Lingüística Española Actual XX/2:175-215.

Halmøy, Jane-Odile (1982): Le Gérondif. Éléments pour une description syntaxique et sémantique. Université de Trondheim: Tapir (Tesis doctoral).

Hantson, André (1992): “Case Assignment and Be-Deletion in Non Finite Clauses, with special reference to (absolute) free adjuncts», Belgian Journal of Linguistics 7:75-94.

Hoff, François (1989): "Les ablatifs absolus irréguliers: un nouvel examen du problème”, en Subordination and Other Topics in Latin. Proceedings of the Third Colloquium on Latin Linguistics (Bologna, 1-5 Aprile 1985), Gualtiero Calboli (ed.), pp. 401-423. Amsterdam/ Philadelphia: John Benjamins. 
Hricsina, Jan (2015): “Análise corporal do gerúndio em português”, Études Romanes de Brno 36/2:267-284.

Hunnius, Klaus (2006): "Prestige und Sprachwandel. Zur Entwicklung des Gérondif und Partizip Präsens im Französischen”, Romanistisches Jahrbuch 56:83-96.

Keniston, Hayward (1937): The syntax of Castilian prose. Chicago: The University of Chicago Press.

Koch, Peter y Wulf Oesterreicher (1990[2011]): Gesprochene Sprache in der Romania: Französisch - Italienisch - Spanisch (Romanistische Arbeitshefte 31). Berlin/New York: De Gruyter.

Koller, Werner (1984): "Übersetzungen ins Deutsche und ihre Bedeutung für die deutsche Sprachgeschichte", en Sprachgeschichte. Ein Handbuch zur Geschichte der deutschen Sprache und ihrer Erforschung, Wemer Besch, Oskar Reichmann y Stefan Sonderegger (eds.), tomo I, pp. 112-129. Berlin/New York: De Gruyter.

Kortmann, Bernd (1991): Free adjuncts and Absolutes in English. Problems of control and interpretation. London/New York: Routledge.

Lapesa, Rafael (2000): Estudios de morfosintaxis histórica del español. Edición de Rafael Cano Aguilar y M. ${ }^{\text {a }}$ Teresa Echenique Elizondo. Madrid: Gredos.

Lardon, Sabine y Marie-Claire Thomine (2009): Grammaire du français de la Renaissance. Étude morphosyntaxique. Paris: Garnier.

Lausberg, Heinrich (1972): Romanische Sprachwissenschaft. III: Formenlehre. Berlin: De Gruyter.

Lázaro Carreter, Fernando (1980): “La lengua de los refranes. ¿Espontaneidad o artificio?”, en Estudios de Lingüística, Fernando Lázaro Carreter, pp. 219-232. Barcelona: Crítica.

Lecointe, Jean (1997): "Le style en -ant au XVIe siècle en France : conscience syntaxique et options stylistiques”, L'Information Grammaticale 75:10-14.

Ledgeway, Adam (2012): From Latin to Romance. Oxford: Oxford University Press.

[LLT-A] = Library of Latin Texts - Series A. Brepols Publishers' Databases (http://apps.brepolis.net/BrepolisPortal/default.aspx) [acceso: 11.08.2017].

Loporcaro, Michele, Lorenza Pescia y Maria Ana Ramos (2004): “Costrutti dipendenti participiali e participi doppi in portoghese", Revue de linguistique romane LXVIII:15-46.

Lorian, Alexandre (1968): "Les latinismes de syntaxe en français", en Actas del XI Congreso Internacional de Lingüistica y Filología Románicas, Antonio Quilis, Ramón B. Carril y Margarita Cantarero (eds.), tomo III, pp. 1263-1280. Madrid: Consejo Superior de Investigaciones Científicas.

Lorian, Alexandre (1973): Tendances stylistiques dans la prose narrative française au XVIe siècle. Paris: Klincksieck.

Marazzini, Claudio (1993): "Le teorie", en Storia della lingua italiana. Volume primo: I luoghi della codificazione, Luca Serianni y Pietro Trifone (eds.), pp. 232-329. Torino: Einaudi.

Marques Barreiro, Anabela (1998): Propriedades Sintáctico-Semânticas dos Particípios Passados em Português Europeu. Universidade Nova de Lisboa (Tese de Mestrado).

Meilán García, Antonio J. (1991a): "El comportamiento funcional del "participio de presente" en el castellano medieval y renacentista", Revista de Filología Universidad de La Laguna 10:281-297.

Meilán García, Antonio J. (1991b): La oración simple en la prosa castellana del siglo XV. Oviedo: Departamento de Filología Española.

Menoni, Viviana (1982): "Formazione e storia del gerundio composto nell'italiano antico", Studi di Grammatica Italiana XI:5-88. 
Milani, Celestina (2009): "L'ablativo assoluto negli Itineraria ad loca sancta", en Varia Linguistica, Celestina Milani (ed. de Rosa Bianca Finazzi y Paola Tornaghi), pp. 153-170. Milano: EDUCatt.

Müller-Lancé, Johannes (1994): Absolute Konstruktionen vom Altlatein bis zum Neufranzösischen. Tübingen: Narr.

Muñío Valverde, José Luis (1995): "Pervivencia del participio de presente activo en el español antiguo", Romanistisches Jahrbuch 46:231-250.

Narbona Jiménez, Antonio (1996): “Construcciones ¿absolutas? de participio”, en Actas del III Congreso Internacional de Historia de la Lengua Española: Salamanca, 22-27 de noviembre de 1993, Alegría Alonso González (ed.), tomo I, pp. 457-469. Madrid: Arco/ Libros.

Narbona Jiménez, Antonio (2000[2015]): “Para una sintaxis del español coloquial”, en Sintaxis del español coloquial, Antonio Narbona Jiménez, pp. 117-134. Sevilla: Editorial de la Universidad de Sevilla.

Nykrog, Per (1957): "L'influence latine savante sur la syntaxe du français", Travaux du Cercle Linguistique de Copenhague 11:89-114.

Oesterreicher, Wulf (1994): "El español en textos escritos por semicultos. Competencia escrita de impronta oral en la historiografía indiana (s. XVI)", en El español de América en el siglo XVI. Actas del Simposio del Instituto Ibero-Americano de Berlín, 23 y 24 de abril de 1992, Jens Lüdtke (ed.), pp. 155-190. Frankfurt a. M.: Vervuert (Bibliotheca Ibero-Americana, 48).

Pagliaro, Antonio y Walter Belardi (1968): Linee di storia linguistica dell'Europa. Roma, Edizioni dell'Ateneo.

Pato, Enrique (2014): "En llegando los datos la intuición se matiza. El gerundio preposicional en la historia de la lengua española", RILCE 30/3:833-860.

Pfister, Max (1973): “Die sprachliche Charakterisierung”, en Studien zur Prosa des Florentiner Vulgärhumanismus im 15. Jahrhundert, August Buck, y Max Pfister, pp. 197-233. München: Wilhelm Fink.

Pfister, Max (1978): "Die Bedeutung der "volgarizzamenti" lateinischer Texte für die Herausbildung der literarischen Prosasprache", en Studien zu den "vulgarizzamenti" römischer Autoren in der italianischen Literatur des 13. und 14. Jahrhunderts, August Buck y Max Pfister, pp. 45-87. München: Wilhelm Fink.

Pons Rodríguez, Lola (2015a): "Prejuicios y apriorismos en la investigación histórica sobre marcadores discursivos (con algunas notas sobre así las cosas)", en Les marqueurs du discours dans les langues romanes: une approche contrastive, Margarita Borreguero/Sonia Gómez-Jordana Ferrary (eds.), pp. 285-303. Limoges: Lambert Lucas.

Pons Rodríguez, Lola (2015b): "La lengua del Cuatrocientos más allá de las Trescientas", en Actas del IX Congreso Internacional de Historia de la Lengua Española (Cádiz, sep-

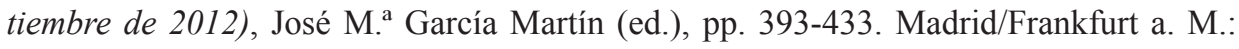
Iberoamericana/Vervuert.

Pountain, Cristopher (2010): "Latin and the structure of written Romance", en The Cambridge History of the Romance Languages. Volume I: Structures, Martin Maiden, John Ch. Smith y Adam Ledgeway (eds.), pp. 606-659. Cambridge: Cambridge University Press,.

Raible, Wolfgang (1996): "Relatinisierungstendenzen”, en Lexikon der Romanistischen Linguistik (LRL) Band II/1: Latein und Romanisch. Historisch-vergleichende Grammatik der romanischen Sprachen, Günter Holtus, Michael Metzeltin y Christian Schmitt (eds.), pp. 120-134. Tübingen: Niemeyer.

Reese, Susanne (1991): Gerundialkonstruktionen im Spanischen. Tübingen, Narr. 
Rohlfs, Gerhard (1969): Grammatica storica della lingua italiana e dei suoi dialetti. Sintassi e formazione delle parole. Traducción de Temistocle Franceschi y Maria Caciagli Fance1li. Torino: Einaudi.

Santiago Lacuesta, Ramón (1979): La primera versión castellana de La Eneida, de Virgilio. Madrid: Anejo XXXVIII del Boletín de la Real Academia Española.

Sarré, Nguissaly (2000): "Morphologie des formes en -ant en moyen français", L'Information Grammaticale 86:40-52.

Scavuzzo, Carmelo (1994): "I latinismi del lessico italiano", en Storia della lingua italiana. Volume secondo: Scritto e parlato, Luca Serianni y Pietro Trifone (eds.), pp. 469-494. Torino: Einaudi.

Segre, Cesare (1963): Lingua, stile e società. Studi sulla storia della prosa italiana. Milano: Feltrinelli.

Serianni, Luca (1989[2010]): Grammatica italiana. Italiano comune e lingua letteraria. Con la collaborazione di Alberto Castelvecchi. Novara: UTET Università.

Serianni, Luca (1993): "La prosa", en Storia della lingua italiana. Volume primo: I luoghi della codificazione, Luca Serianni y Pietro Trifone (eds.), pp. 451-577. Torino: Einaudi.

Sneyders de Vogel, Kornelis (1919): Syntaxe historique du français. Groningen/Den Haag: J. B. Wolters.

Steele, Robert Benson (1902): "The Ablative Absolute in Livy", The American Journal of Philology 23/4:413-427.

Stein, Peter (1997): Untersuchungen zur Verbalsyntax der Liviusübersetzungen in die romanischen Sprachen. Tübingen: Niemeyer.

Stump, Gregor T. (1985): The Semantic Variability of Absolute Constructions. Dordrecht/ Boston/Lancaster: D. Reidel.

Suárez Fernández, Merecedes (1996): "Las construcciones absolutas en el castellano primitivo: su estructura interna", en Actas del III Congreso Internacional de Historia de la Lengua Española: Salamanca, 22-27 de noviembre de 1993, Alegría Alonso González (ed.), tomo I, pp. 583-595. Madrid: Arco/Libros.

Tarriño Ruiz, Eusebio y José Miguel Baños Baños (2009): “Temporales y causales», en Sintaxis del latín clásico, José Miguel Baños Baños (coord.), pp. 601-632. Madrid: Liceus.

Tekavčić, Pavao (1972): Grammatica storica dell'italiano. Volume II: Morfosintassi. Bologna: il Mulino.

Tesi, Ricardo (2001): Storia dell'italiano. La formazione della lingua comune dalle origini al Rinascimento. Roma/Bari: Laterza.

Vitale, Maurizio (1996): La lingua del Canzoniere (Rerum Vulgarium Fragmenta) di Francesco Petrarca. Padova: Antenore.

Weerenbeck, Bemard H. J. (1927): Participe présent et gérondif. Utrecht/Paris: Champion.

Winter-Froemel, Esme, Araceli López Serena, Álvaro S. Octavio de Toledo y Huerta y Barbara Frank-Job (2015): “Zur Einleitung / Introducción”, en Diskurstraditionen, Diskurstraditionelles und Einzelsprachliches im Sprachwandel / Tradiciones discursivas, tradicionalidad discursiva e idiomaticidad en el cambio lingüistico, Esme Winter-Froemel, Araceli López Serena, Álvaro S. Octavio de Toledo y Huerta y Barbara Frank-Job (eds.), pp. 1-27. Tübingen: Narr (ScriptOralia 141). 